\title{
Is There Enough Evidence for the Association of GN $\beta 3$ C825T Polymorphism With Functional Dyspepsia and Irritable Bowel Syndrome?: Author's Reply
}

TO THE EDITOR: We appreciate the interest and comments ${ }^{1}$ on our paper, which was published in the July 2012 issue of this journal. ${ }^{2}$ We totally agree with the comment that many factors including heterogeneity of the disease, sample size, sample selection or racial difference may contribute to conflicting results of the genetic association studies in functional gastrointestinal disorders. Based on the reports showing the association of G-protein beta3 subunit (GN $\beta 3$ ) C825T polymorphism with functional dyspepsia (FD) and irritable bowel syndrome (IBS), we hypothesized that GN 33 C825T polymorphism is associated with the overlap of FD and IBS. However, we failed to demonstrate the positive association. Moreover, in our study, GN $\beta 3$ C $825 \mathrm{~T}$ polymorphism was not significantly associated with the existence of FD alone or IBS alone. Four Korean studies including ours have been published in the literature. ${ }^{2-5}$ Among them, 2 studies showed the positive association ${ }^{4,5}$ and the others presented the negative association of GN $\beta 3$ C825T polymorphism with FD or IBS. ${ }^{2,3}$ The results were not consistent even in the former studies.

The $825 \mathrm{~T}$ allele is associated with enhanced G-protein activation and, thereby, increased cellular or physiologic responses. ${ }^{6}$ However, the $\mathrm{CC}$ genotype is characterized by diminished signal transduction responses. The genotype, associated with FD or IBS, should be different according to the distribution of subtypes. Theoretically, significant differences in the genotype frequency are more likely to exist between the subtypes of FD or IBS and the controls rather than between the entire group of FD or IBS and the control group. Previous Western studies have also shown conflicting results. ${ }^{7-10}$ The CC genotype is associated with unexplained dyspepsia in Germany. ${ }^{7}$ Whereas, homozygous T or C alleles of the GN $\beta 3$ C825T polymorphism is associated with meal-unrelated dyspepsia in a US community. ${ }^{8}$ Tertiary referral FD in the Netherlands is reported to be associated with the $825 \mathrm{~T}$ allele of the GN $\beta 3$ gene. ${ }^{9}$ There is a report showing that GN $\beta 3$ C825 T polymorphism is not associated with lower functional gastrointestinal disorders. ${ }^{10}$ Similarly, studies on a genetic polymorphism in the gene encoding for activity of the serotonin transporter protein in IBS patients have produced inconsistent results.

FD and IBS are symptom-based disorders without measurable biomarkers. In addition, FD or IBS consists of subtypes with different phenotypes and pathophysiologic mechanisms. Because of those complex features, there are some fundamental problems in evaluating the genetic basis of FD and IBS. The pathophysiological mechanisms underlying symptom-based phenotypes are likely to be heterogeneous. Different biological mechanisms can produce similar symptom patterns. Individuals with delayed gastric emptying and those without such changes both can meet the postprandial distress syndrome diagnostic criteria as well as the FD symptom criteria. FD and IBS are common diseases and present diverse traits. The complex traits result from common variants with a relatively high frequency, but the effect size of each variant is relatively small. ${ }^{11}$ Moreover, the clinical phenotypes in an individual are not stable over time. Diverse environmental factors as well as genetic factors are required to develop a clinical phenotype. So, many factors may be involved in conflicting results of the genetic association studies in functional gastrointestinal disorders. We concur with the comments that physiologic studies that deal with the effect of the GN $\beta 3$ C825T polymorphism on gastrointestinal motor and sensory functions and pharmacogenomic studies on the response to the specific drugs are necessary.

Kwang Jae Lee

Department of Gastroenterology, Ajou University School of Medicine Suwon, Gyeonggi-do, Korea 
1. Park MI. Is there enough evidence for the association of GN $\beta 3$ C825T polymorphism with functional dyspepsia and irritable bowel syndrome? J Neurogastroenterol Motil 2012;18:348-349.

2. Kim HG, Lee KJ, Lim SG, Jung JY, Cho SW. G-protein beta3 subunit $\mathrm{C} 825 \mathrm{~T}$ polymorphism in patients with overlap syndrome of functional dyspepsia and irritable bowel syndrome. J Neurogastroenterol Motil 2012;18:205-210.

3. Park HY, Jahng JH, Lee YJ, Park H, Lee SI. [Serotonin transporter gene and $\mathrm{G}$-protein $\beta 3 \mathrm{C} 825 \mathrm{~T}$ gene polymorphism in patients with functional dyspepsia and irritable bowel syndrome.] Korean J Neurogastroenterol Motil 2009;15:58-64. [Korean]

4. Lee HJ, Lee SY, Choi JE, et al. G protein beta3 subunit, interleukin-10, and tumor necrosis factor-alpha gene polymorphisms in Koreans with irritable bowel syndrome. Neurogastroenterol Motil 2010;22:758-763.

5. Park CS, Uhm JH. Polymorphisms of the serotonin transporter gene and G-Protein $\beta 3$ subunit gene in Korean children with irritable bowel syndrome and functional dyspepsia. Gut Liver 2012;6:223228.

6. Baumgart D, Naber C, Haude M, et al. Protein beta3 subunit $825 \mathrm{~T}$ allele and enhanced coronary vasoconstriction on alpha(2)-adreno- ceptor activation. Circ Res 1999;85:965-969.

7. Holtmann G, Siffert W, Haag S, et al. G-protein $\beta 3$ subunit 825 CC genotype is associated with unexplained (functional) dyspepsia. Gastroenterology 2004;126:971-979.

8. Camilleri CE, Carlson PJ, Camilleri M, et al. A study of candidate genotypes associated with dyspepsia in a U.S. community. Am J Gastroenterol 2006;101:581-592.

9. Van Lelyveld N, Linde JT, Schipper M, Samsom M. Candidate genotypes associated with functional dyspepsia. Neurogastroenterol Motil 2008;20:767-773.

10. Andresen V, Camilleri M, Kim HJ, et al. Is there an association between GNB3-C825T genotype and lower functional gastrointestinal disorders? Gastroenterology 2006;130:1985-1994.

11. Diatchenko L, Slade GD, Nackley AG, et al. Genetic basis for individual variations in pain perception and the development of a chronic pain condition. Hum Mol Genet 2005;14:135-143.

\section{Conflicts of interest: None.}

